NASA Technical Memorandum 105720

AIAA-92-3098

\title{
Comparative Study of Turbulence Models in Predicting Hypersonic Inlet Flows
}

Kamlesh Kapoor, Bernhard H. Anderson and Robert J. Shaw

Lewis Research Center

Cleveland, Ohio

Prepared for the

28th Joint Propulsion Conference and Exhibit

cosponsored by the AIAA, SAE, ASME, and ASEE

Nashville, Tennessee, July 6-8, 1992 


\title{
Comparative Study of Turbulence Models in Predicting Hypersonic Inlet Flows
}

\author{
Kamlesh Kapoor, Bernhard H. Anderson, and Robert J. Shaw \\ NASA Lewis Research Center \\ Cleveland, Ohio 44135
}

\begin{abstract}
$\underline{\text { Abstract }}$
A numerical study was conducted to analyze the performance of different turbulence models when applied to the hypersonic NASA P8 inlet. Computational results from the PARC2D code, which solves the full two-dimensional Reynolds-averaged Navier-Stokes equations, have been compared with experimental data. The zero-equation models considered for the study were the Baldwin-Lomax model, the Thomas model, and a combination of the Baldwin-Lomax and Thomas models; the two-equation models considered were the Chien model, the Speziale model (both low Reynolds number), and the Launder and Spalding model (high Reynolds number). The Thomas model performed best among the zero-equation models, and predicted good pressure distributions. The Chien and Speziale models compared very well with the experimental data, and performed better than the Thomas model near the walls.
\end{abstract}

\section{Nomenclature}

k turbulent kinetic energy

$M$

Mach number

$p$

static pressure

$P_{p} \quad$ pitot pressure

$P_{t} \quad$ total pressure

$R e \quad$ Reynolds number

$T_{t} \quad$ total temperature

$u_{\tau} \quad$ friction velocity, $\sqrt{\tau_{w} / \rho_{w}}$

*National Research Council-NASA Research Associate. Member AIAA
$\mathrm{X}$

XREF

$y^{+}$

$\mathrm{Y}$

$\delta$

$\epsilon$

$\nu$

$\rho$

$\tau_{w}$

Subscripts:

$w$

$\infty$

evaluated at wall

tunnel free stream condition axial distance from the leading edge of the centerbody

inlet cowl height

law-of-the-wall coordinate, $u_{\tau} Y / \nu_{w}$

vertical distance from the centerbody

boundary-layer thickness

dissipation rate of turbulence energy

kinematic viscosity

density

wall shear stress

\section{Introduction}

Future hypersonic cruise vehicles will require a highly integrated and efficient propulsion system. Much of the success will depend on the progress made in computational fluid dynamics for high-speed flows. Hypersonic flows are characterized by the presence of high Mach numbers in the inviscid region, high gradients of the flow variables in the vicinity of shocks, real gas effects, and thick heated boundary layers. To accurately model such complex flows, one needs to consider new turbulence and transition models, equilibrium and non-equilibrium real 
gas effects, and the capability to resolve high flow gradients. At present, a number of very powerful and efficient computational codes are available to solve the full NavierStokes equations. However, the success of these codes depends on, among other factors, the type of turbulence modeling being implemented in them. The objective of the present paper is to compare the performance of a variety of turbulence models for the prediction of hypersonic inlet flows.

The NASA P8 inlet, ${ }^{1}$ which represents cruise conditions of a typical hypersonic air-breathing vehicle, was selected as a test case for this study. Recently, an AGARD working group ${ }^{2}$ also selected the P8 inlet for comparing numerical results.

A relevant review of turbulence modeling is available in Ref. 3. In the past, $\mathrm{Ng}$ et al. ${ }^{4}$ made an effort to compare the performance of different turbulence models for the calculation for a two-dimensional hypersonic inlet flow field and compared their results with experimental data from the P8 inlet. They used the McDonaldCamarata model ${ }^{5}$ and the Baldwin-Lomax ${ }^{6}$ model (both zero-equation models) and the turbulence kinetic energy model $^{7}$ (one-equation model) in a parabolized NavierStokes (PNS) code, and obtained results for both fully turbulent flow throughout the inlet and while specifying the transition from laminar to turbulent flow. In their study, only the Baldwin-Lomax model was implemented in a full Navier-Stokes (NS) equation code. They concluded that the McDonald-Camarata model, with a user-specified transition of the boundary layer, gave the best solution among the three models. The BaldwinLomax model predicted separation for both the NS and PNS codes, where none existed in the experiments. However, their study was not complete and conclusive since it was primarily limited to the PNS code, and only the Baldwin-Lomax turbulence model was implemented in a full Navier-Stokes equations code. Moreover, they did not include a two-equation turbulence model in their study. Therefore, there is a need to further investigate this problem in order to find the best existing turbulence model to predict the hypersonic inlet flow field.

The PARC2D code, which solves the full twodimensional Reynolds-averaged Navier-Stokes equations, was selected for this study. The PARC code has been used previously for a variety of supersonic and hypersonic configurations, ${ }^{8,9}$ but only the Balwin-Lomax turbulence model was used. These investigations demonstrated the capability of the PARC code to simulate hypersonic inlet flows.

The results are presented for six versions of zero- and two-equation turbulence models: the Baldwin-Lomax, ${ }^{6}$
Thomas, ${ }^{10}$ and a combination of the Baldwin-Lomax and Thomas models, which are all zero-equation models; and the Chien, ${ }^{11}$ Speziale et al. ${ }^{12}$ (both low Reynolds number), and Launder and Spalding ${ }^{13}$ (high Reynolds number) models, which are two-equation turbulence models.

\section{Experimental Background}

The experimental investigation was conducted at NASA Ames' 3.5-Foot Hypersonic Wind Tunnel to determine the internal flow characteristics of a typical inlet on a hypersonic air-breathing vehicle operating at cruise conditions. The geometry of the inlet model tested is shown in Fig. 1. The inlet was a Mach 7.4 rectangular mixed-compression design with exiting supersonic flow. The model has an internal compression ratio of 8 and thus is referred to as the $\mathrm{P} 8$ inlet. Inlet cowl height (XREF) was $18.33 \mathrm{~cm}$, forebody length was $82.28 \mathrm{~cm}$, overall length was $136.2 \mathrm{~cm}$, and width was $35.56 \mathrm{~cm}$. A $6.5^{\circ}$ forebody wedge was designed to match an inlet entrance Mach number of 6 at a test Mach number of 7.4, allowing for boundary layer displacement effects. The wedge was cooled to provide a uniform surface temperature of $0.375 T_{t \infty}$, where the free stream total temperature $\left(T_{t_{\infty}}\right)$ was $811^{\circ} \mathrm{K}$. The free stream unit Reynolds number $\left(R e_{\infty}\right)$ was $8.86 \times 10^{6} / \mathrm{m}$. The transition point on the centerbody was found experimentally to be at approximately 40 percent of the distance between the wedge leading edge and the inlet entrance. The transition point in the cowl boundary layer was approximately halfway between the cowl leading edge and the throat station. The details of the experiments can be found in Ref. 1. The internal contours were designed to provide high total pressure recovery and uniform static pressure at the throat. To achieve this goal, it was necessary to cancel the cowl lip generated shock at the centerbody by appropriate design of the centerbody contour. The design criteria of the shock cancellation at the centerbody was not satisfied experimentally because of inadequate treatment of the interaction of the cowl-generated shock and the turbulent centerbody boundary layer. The centerbody boundary layer was found to be of considerable size (approximately 15 percent of the inlet height at the point of the cowl shock and centerbody interaction). This interaction produced a downstream shock pattern that yielded significant nonuniformities at the inlet throat.

This realistic inlet geometry, with strong viscousinviscid interactions and the availability of extensive experimental data, provided an excellent opportunity to verify the numerical algorithm and turbulence models for the application of predicting the hypersonic inlet flow field. 


\section{Turbulence Models}

Only a brief description of the turbulence models used for the present study is given here because of limited space.

The Baldwin-Lomax model was chosen for the study because it is one of the most widely used turbulence models. The model is an algebraic eddy viscosity turbulence model for separated flows, and its use avoids the necessity for finding the edge of the boundary layer. In this two-layer turbulence model, the vorticity generated near a solid wall is used to determine the length scales in the turbulent boundary layer. The details of the model are given in Ref. 6.

Another turbulence model used in the present calculations is also an algebraic eddy viscosity model and is loosely based on the Thomas formulation ${ }^{10}$ of the Baldwin and Lomax model. ${ }^{6}$ This model is referred to as the Thomas model in this paper. The details of the Thomas model can be found in Refs. 10 and 14 .

In the case of the combination of the Baldwin-Lomax and Thomas models, the code is designed to calculate the value of turbulent viscosity by both the Thomas and Baldwin-Lomax methods separately. Then it takes the larger of two values in the unbounded flow region and the smaller value near the no-slip boundary condition.

In the present study, two low-Reynolds-number twoequation turbulence models were used. Since the wall shear stress is computed directly from the velocity gradient without having any preassumption of the velocity profile near the walls, the degree of empiricism is reduced considerably for these models.

The Chien low-Reynolds-number model, ${ }^{11}$ as modified by Nichols ${ }^{15}$ for compressibility effects, was used in the present study. All the functions of Chien's model are simple algebraic functions and do not involve any differential operators. Therefore, this model is relatively easy to implement.

The other low-Reynolds-number two-equation model used in this effort is by Speziale et al. ${ }^{12}$ The numerical solution for the $k-\epsilon$ equations is that of Nichols. ${ }^{15}$ Modifications were made to improve the numerical stability of the turbulence model and to extend the model to compressible flows.

The high-Reynolds-number two-equation turbulence model used in the present study is by Launder and Spalding. ${ }^{13}$ One of the assumptions made in deriving the wall functions for $k$ and $\epsilon$ is that the production and dissipation rates of the turbulence kinetic energy are in equilibrium. This assumption is strictly valid only in the logarithmic region of the boundary layer. Therefore, the first grid point must be placed in the logarithmic layer for correct use of the wall functions. The wall functions used in this model are essentially semi-empirical correlations connecting conditions at the first grid points and those at the wall.

\section{Method of Solution}

The PARC2D code, selected for this study, was developed at the Arnolds Engineering Development Center. The PARC code, which is available in both twoand three-dimensional versions, solves the full Reynolds averaged Navier-Stokes equations in strong conservation form with the Beam and Warning approximate factorization. The code uses a central differencing scheme in a generalized curvilinear coordinate system with implicit and explicit second- and fourth-order artificial dissipation. The details of the code can be found in Ref. 14 .

The computational grid used in this study was $221 \times 91$, nonuniform in the $\mathrm{X}$ direction. The grid was packed on both ends from the wedge leading egde to the cowl leading edge, and was also geometrically stretched from the cowl leading edge to the outflow boundary. To resolve the viscous layer, the grid lines were packed close to the centerbody and cowl walls using hyperbolic tangent functions such that the first grid line was located at a $y^{+}$of approximately 1.0 away from the walls. As discussed earlier, the high-Reynolds-number turbulence model requires the first grid line to be in the logarithmic layer for proper use of wall functions. Therefore, a separate grid had to be made for the Launder and Spalding model. The grid was kept the same in the X direction, but a $y^{+}$ of approximately 30 was used away from the walls. The grid size was also kept the same $(221 \times 91)$ in this case.

A nonreflective boundary condition, ${ }^{9}$ using a simple Mach wave extrapolation, was applied on the upper boundary upstream of the cowl to let the shock wave from the wedge pass through the boundary. The flow field at the inflow boundary, which is ahead of the inlet wedge leading edge, was held fixed. The extrapolation boundary condition was applied to the outflow boundary. A no-slip isothermal boundary condition was used on all solid walls.

It should be noted that all computations were performed with fully turbulent flow throughout the inlet. The transition points were not simulated in the present calculations because of code limitations.

The computations were performed on the CRAY-YMP supercomputer at NASA Lewis Research Center. The 
code typically required a total of 35 minutes of CPU time to achieve global convergence for the zero-equation models. The computer time increased by approximately four times when the two-equation models were used.

\section{Results and Discussion}

The performance of a hypersonic inlet is significantly affected by the interaction of the shock waves and wall turbulent boundary layers. This interaction becomes more critical at higher Mach numbers, where boundary layer bleed is considered impractical because of the high stagnation temperatures. The interaction between the inlet cowl lip shock and centerbody turbulent boundary layer, particularly, requires careful analysis since the centerbody contours are often designed to cancel the cowl lip shock. The internal contours of the P8 inlet model were designed to provide cancellation of the cowl shock at the centerbody and an isentropic compression to the throat. Nevertheless, a reflected shock was found experimentally, which further interacted with the cowl and centerbody boundary layers upstream of the throat. This significantly affected the flow structure at the inlet throat. The present computations were able to capture these flow characteristics.

The computed density, pressure, and Mach number contours for the Thomas turbulence model are shown in Fig. 2. The contours for the other turbulence models were essentially similar to those of the Thomas model. It is clearly shown in the figure that the cowl shock, after interacting with the centerbody turbulent boundary layer, was reflected downstream and interacted with the cowl turbulent boundary layer. It was then reflected from the cowl and interacted again with the centerbody turbulent boundary layer before it left the inlet.

The computational results are presented in the form of surface pressure distributions on the centerbody and cowl of the inlet model, and the pitot pressure and total temperature distributions at many stations from the inlet entrance to the throat of the inlet. The results are compared with the corresponding experimental data of Ref. 1.

The surface pressure distributions on the centerbody are shown in Fig. 3. The axial distances are nondimensionalized with the inlet cowl height. As shown in the figure, the Thomas model compares very well with the experimental data, while the Baldwin-Lomax model and its combination with the Thomas model do not compare as accurately. The results obtained using the Baldwin-Lomax model show the existence of a separation bubble on the centerbody in the immediate region of cowl-lip-shock/centerbody-boundary-layer interaction. No separation was reported in the experiment. $\mathrm{Ng}$ et al. ${ }^{4}$ also reported the presence of a separation bubble when they used the Baldwin-Lomax model. This indicates that the Baldwin-Lomax model fails in regions of shock-wave/boundary-layer interaction at hypersonic speeds. On the other hand, the Thomas, Chien, and Speziale models do not predict separation, but are able to successfully simulate the complex flow field resulting from the interaction of the cowl shock with the centerbody turbulent boundary layer. The Launder and Spalding model overpredicts the pressure rise at the inlet throat but predicts no separation on the centerbody.

Figure 3 shows that all of the present computations disagree slighly with the experimental data near the location of the cowl shock wave and centerbody turbulent boundary layer interaction. This difference in the computational results with the experimental data may be attributed to the fact that the present computations were performed with fully turbulent flow throughout the inlet, without simulated transition points. As mentioned earlier, the transition point on the centerbody was found experimentally to be at approximately 40 percent of the distance between the wedge leading edge and the inlet entrance. This may have resulted in thicker boundary layers in the present computations as compared with those of experiments. The interaction of the cowl shock with a thicker turbulent boundary layer will produce a stronger upstream influence, which causes an upstream shift in pressure distributions.

The pressure distributions on the cowl surface are presented in Fig. 4. The computed results show the flow compression and impingement of the reflected shock wave on the cowl. The expansion ahead of the reflected shock impingement, which is a feature associated with the shock/boundary-layer interaction on the centerbody, is also visible in the numerical results. The Thomas model results are closest to the experimental data. The Baldwin-Lomax model and its combination with the Thomas model, and the Launder and Spalding model slightly overpredict cowl pressures at the inlet throat. However, the Chien and Speziale models slightly underpredict the cowl pressures at the throat.

The computational and experimental pitot pressures at $\mathrm{X} / \mathrm{XREF}=5.67$, a station upstream of the intersection of the cowl shock with the centerbody, are shown in Fig. 5. The agreement of the numerical results with the experimental data is generally good. The steep rise in the pitot pressure at $\mathrm{Y} / \mathrm{XREF}=0.15$ is due to the presence of the cowl shock. The computed results with the Thomas turbulence model seem to predict the best 
solution among the zero-equation models. The BaldwinLomax model is not able to predict the inlet flow field accurately. All two-equation models are better than the zero-equation models near the centerbody. The Launder and Spalding model produces the sharpest cowl shock, and the calculated boundary layer thickness is much closer to that of experiment as compared with the other turbulence models. The results from the design analysis of Ref. 1 are also shown in the figure. The boundary layer thicknesses on the centerbody and cowl surfaces obtained from the experiments are also marked in the figure.

All of the present computational results overpredicted the pitot pressures in the central region of the inlet. In a recent AGARD report, ${ }^{2}$ it was pointed out that no one has ever matched the experimental data using the stated tunnel conditions of Ref. 1. The many computational results tend to agree with one another, but do not match the experimental data. It was further suspected in Ref. 2 that the conditions stated in Ref. 1 were different in some way from the conditions that were actually present in the tunnel. It should be noted that because of the high sensitivity of hypersonic flows, even small variations in the upstream flow field would lead to larger variations downstream.

The total temperature profile at $\mathrm{X} / \mathrm{XREF}=5.67$ is presented in Fig. 6. The experimental total temperature ratio is less than 1.0 because it was not corrected for the uncertainties in other measurements ${ }^{1}$ The comparison of the computed results with the experimental data is generally good. The two-equation models compare very well with the experimental data, particularly near the centerbody.

The pitot pressure and total temperature distributions at $\mathrm{X} / \mathrm{XREF}=6.09$, the intersection point of cowl shock and centerbody, are shown in Figs. 7 and 8, respectively. The agreement between the computed results and experiment is good, except in the central portion of the inlet, where the pitot pressures overpredict the experimental values. The performance of various turbulence models remains qualitatively the same as for $\mathrm{X} / \mathrm{XREF}=5.67$.

The pitot pressure and total temperature distributions at $\mathrm{X} / \mathrm{XREF}=6.37$, a station just downstream of the reflection of the cowl shock from the centerbody, are presented in Figs. 9 and 10, respectively. As shown in Fig. 9 , the experimental centerbody boundary layer has been compressed by the reflecting shock wave and is comparatively thinner than at the previous station. The reflected shock wave emerges from the boundary layer at $\mathrm{Y} / \mathrm{XREF}$ $=0.025$, as shown by the break in the curve. All of the present computations were able to pick up the emerging shock wave, but the magnitude and location of the emerg- ing shock varied for each turbulence model, as shown in Fig. 9. The design analysis of Ref. 1 is also presented in Fig. 9. The comparison of total temperatures with experimental data is good, as shown in Fig. 10.

The pitot pressures and total temperatures at $\mathrm{X} / \mathrm{XREF}=6.65$, a station upstream of the inlet throat, are shown in Figs. 11 and 12, respectively. The reflected shock from the centerbody interacts with the cowl boundary layer at $\mathrm{X} / \mathrm{XREF}=6.72$, and gets reflected once again. Figure 11 shows that the centerbody boundary layer has been compressed thinner than at the previous station. As shown in Fig. 11, only the Thomas model was able to capture the presence of this reflected shock, while the other turbulence models including all two-equation models completely fail to do so. The comparison of total temperatures with experimental data is qualitatively good, as shown in Fig. 12.

The inlet performance was obtained in terms of pitot pressure, total temperature, and Mach number distributions at the throat. The pitot pressure distribution, presented in Fig. 13, shows a large variation across the throat height due to the presence of the reflected shock wave. The results from the design analysis of Ref. 1 are also shown in the figure. The total temperature distribution at the throat is shown in Fig. 14. The Mach number profile at the throat is presented in Fig. 15. The computed results are in fair agreement with the experimental data. The results from the design analysis of Ref. 1 are also presented in the figure.

\section{$\underline{\text { Conclusions }}$}

A computational study has been carried out to evaluate the performance of various turbulence models in predicting hypersonic inlet flow fields. The PARC2D code, which solves the full two-dimensional Reynoldsaveraged Navier-Stokes equations, has been selected to compare the computational results with available experimental data. The results have been presented for the Baldwin-Lomax, Thomas, and a combination of the Baldwin-Lomax and Thomas models, which are all zeroequation models; and the Chien, Speziale (both low Reynolds number), and Launder and Spalding (high Reynolds number) models, which are two-equation turbulence models.

These models have been evaluated on the basis of comparisons of pitot pressure and total temperature profiles at various axial locations and surface pressure distributions on the centerbody and cowl of the inlet. Based on the present results, the Thomas model compares very well with the experimental data, and it performs best 
among the zero-equation models. The Baldwin-Lomax model and its combination with the Thomas model are not able to resolve the problem of shock wave and boundary layer interaction accurately. The Baldwin-Lomax model predicts separation near the interaction of the cowl shock with the centerbody boundary layer, where none is known to exist in experiments. The Chien and Speziale models compare very well with the experimental data, and perform better than the Thomas model, particularly near the walls. However, the Launder and Spalding model does not perform well as the Chien and Speziale models. Considering the fact that the CPU time required for the Thomas model is far less than the two-equation models, it is concluded that the Thomas model is best suited for the prediction of pressure distributions, and the Chien and Speziale (both-low-Reynolds number twoequation) models are recommended for the prediction of flow quantities near the walls and may be used for the calculation of skin friction and heat transfer coefficients.

\section{Acknowledgment}

This research was conducted while the first author held a National Research Council Research Associateship at NASA Lewis Research Center.

\section{References}

1. Gnos, A.V., Watson, E.C., Seebaugh, W.R., Sanator, R.J., and DeCarlo, J.P. , "Investigation of Flow Fields Within Large-Scale Hypersonic Inlets Models," NASA TN D-7150, 1973.

2. "Air Intakes for High Speed Vehicles," AGARD AR270, Sept. 1991, pp. 183-201.

3. Marvin, J,G., "Turbulence Modeling for Computational Aerodynamics," AIAA Journal, Vol. 21, No. 7, July 1983, pp. 941-955.

4. Ng, W.F., Ajmani, K., and Taylor, A.C., III, "Turbulence Modeling in a Hypersonic Inlet," AIAA Journal, Vol. 27, No. 10, Oct. 1989, pp. 1354-1360.

5. McDonald, H., and Camarata, F.J., "An Extented Mixing Length Approach for Computing the Turbulent Boundary Layer Development," Computation of Turbulent Boundary Layers, Proceedings of the AFOSR-IFP-Stanford Conference, Vol. I, Stanford University, Stanford, CA, 1969, pp. 83-98.

6. Baldwin, B., and Lomax, H., "Thin-Layer Approximation and Algebraic Model for Separated Turbulent Flows," AIAA Paper 78-257, Jan. 1978.
7. Schetz, J.A., Foundations of Boundary Layer Theory for Momentum, Heat and Mass Transfer, Prentice-Hall, Inc., Englewood Cliffs, NJ, 1984, pp.204-212.

8. Reddy, D.R., and Harloff, G.J., "Three-Dimensional Viscous Flow Computations of High Area Ratio Nozzles for Hypersonic Propulsion," Journal of Propulsion and Power, Vol. 7, Jan.-Feb. 1991, pp. 84-89.

9. Reddy, D.R., Benson, T.J., and Weir, L.J., "Comparison of 3-D Viscous Flow Computations of Mach 5 Inlet with Experimental Data," AIAA Paper 900600 , Jan. 1990.

10. Thomas, P.D., "Numerical Method for Predicting Flow Characteristics and Performance of Nonaxisymmetric Nozzles - Theory," NASA CR-3147, 1979.

11. Chien, K.Y., "Predictions of Channel Flow and Boundary Layer Flow with Low Reynolds Number Turbulence Model," AIAA Journal, Vol. 20, No. 1, Jan. 1982, pp. 33-38.

12. Speziale, C.G., Abib, R., and Anderson, E.C., "A Critical Evaluation of Two-Equation Models for Near Wall Turbulence," NASA CR-182068, 1990.

13. Launder, B.E., and Spalding, D.B., "The Numerical Computation of Turbulent Flows," Computer Methods in Applied Mechanics and Engineering, Vol. 3, Mar. 1974, pp. 269-289.

14. Cooper, G.K., "The PARC Codes," Arnold Engineering Development Center, Tullahoma, TN, AEDC-TR-87-24, Oct. 1987.

15. Nichols, R.H., "A Two-Equation Model for Compressible Flows," AIAA Paper 90-0494, Jan. 1990. 

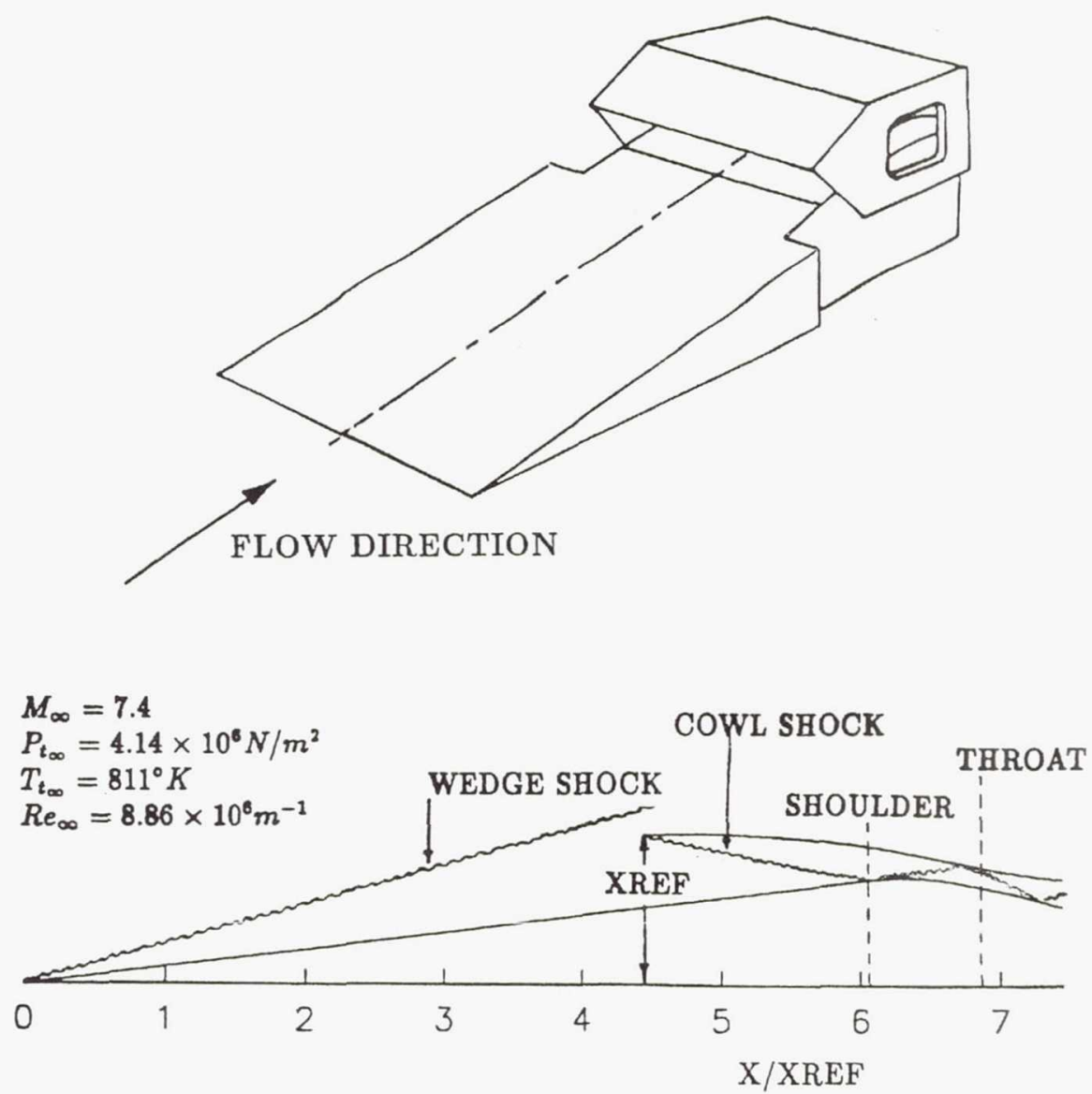

Figure 1.-Schematic diagram of P8 inlet model. 
Page intentionally left blank 


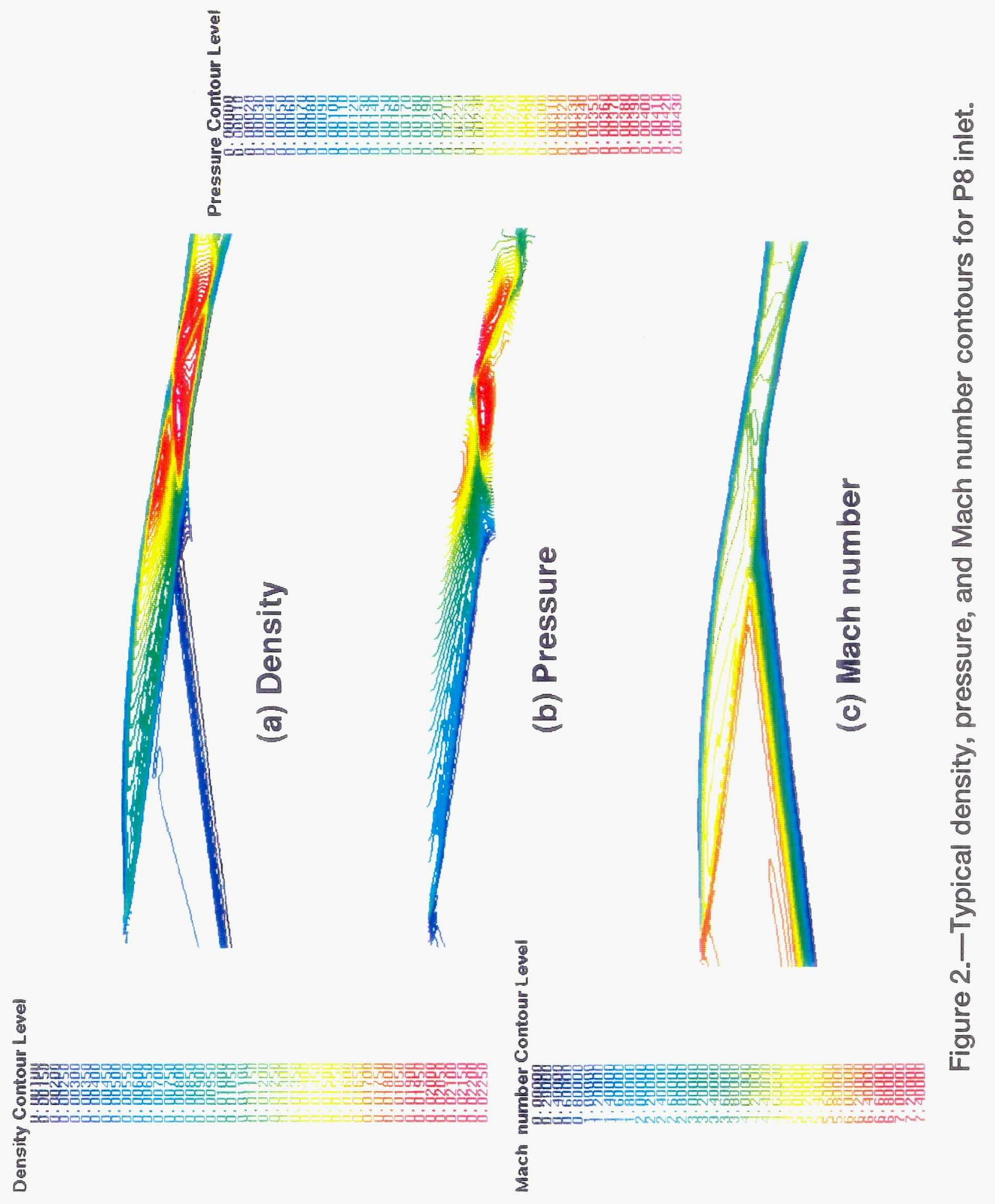


Page intentionally left blank 


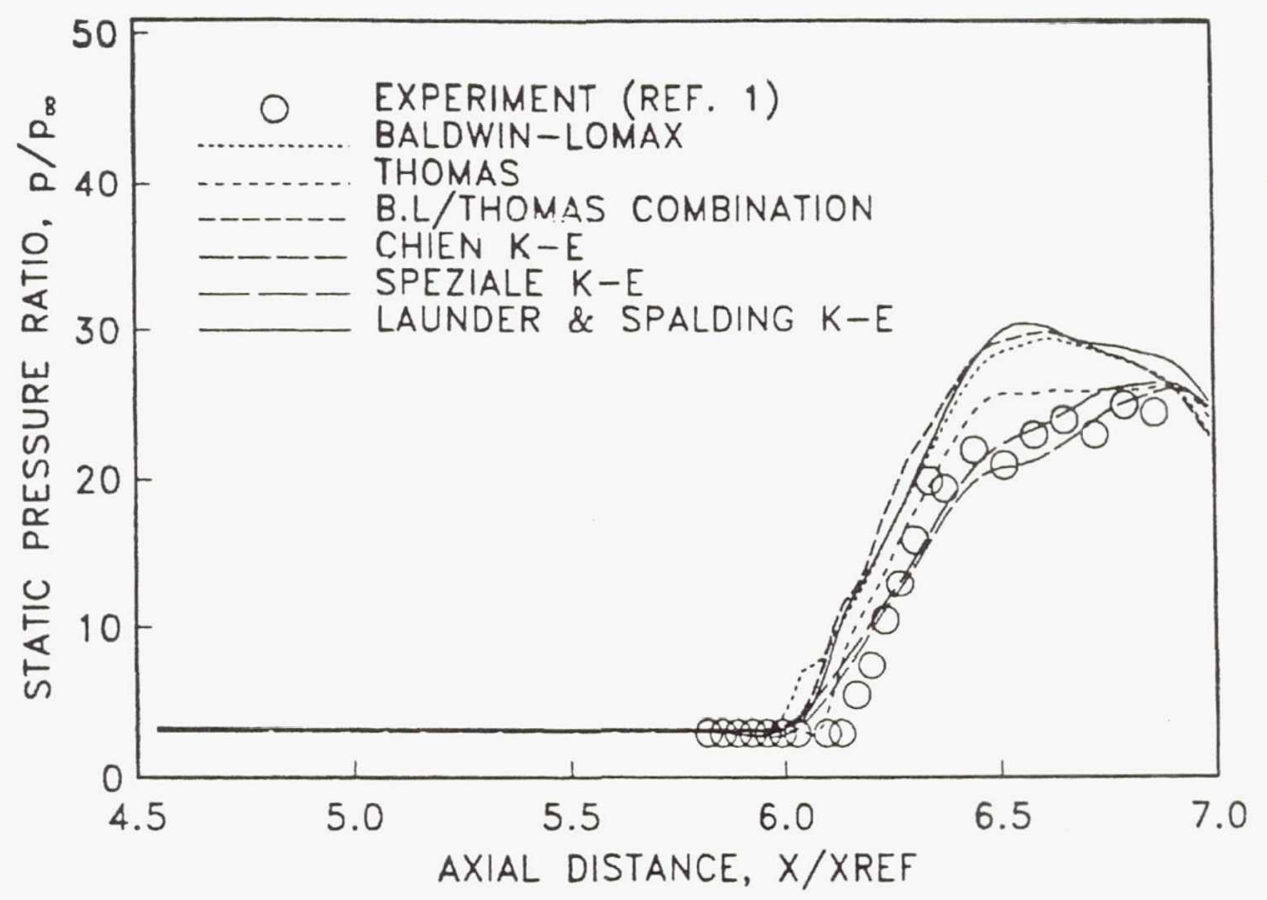

Figure 3.-Surface pressure distribution on the centerbody.

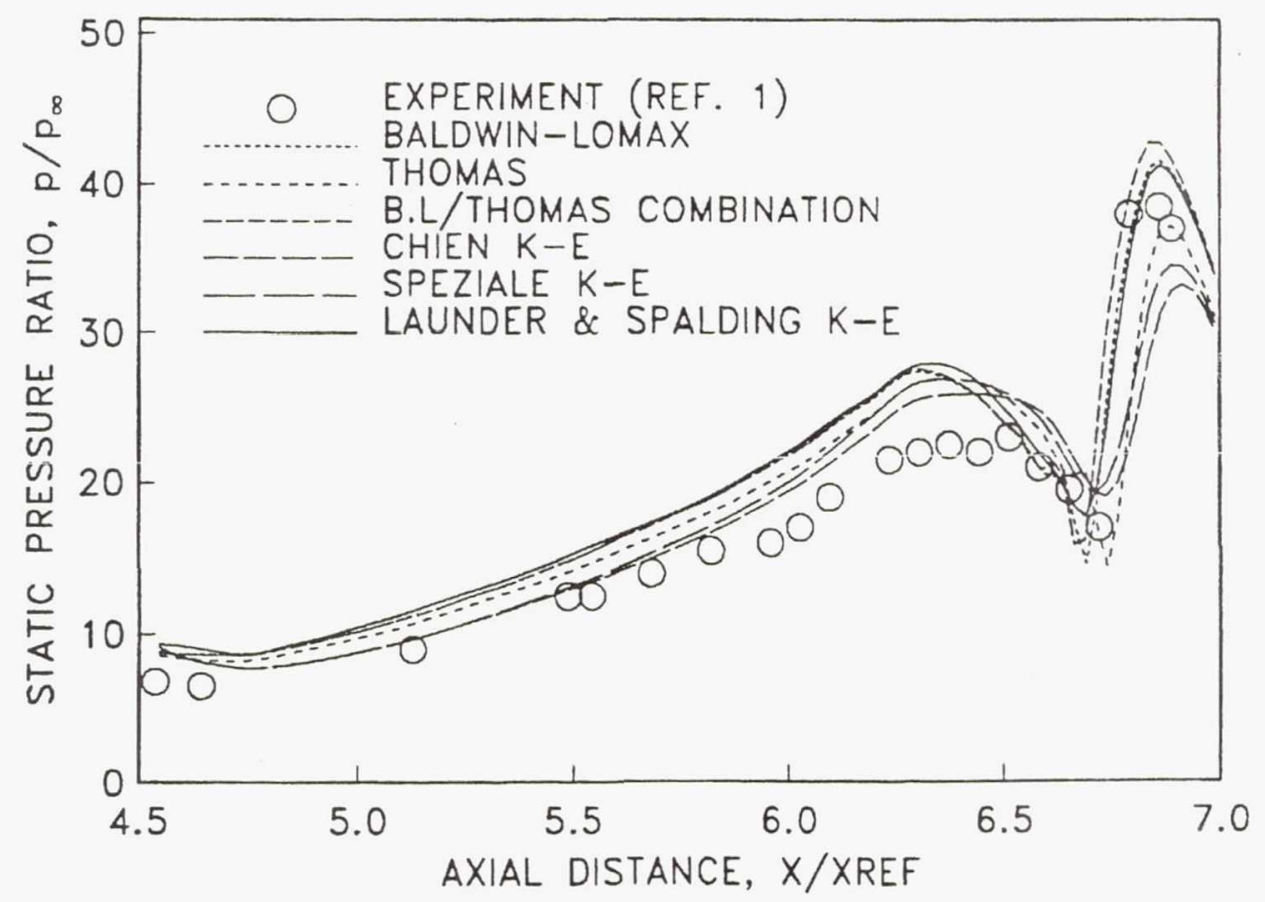

Figure 4.-Surface pressure distribution on the cowl. 


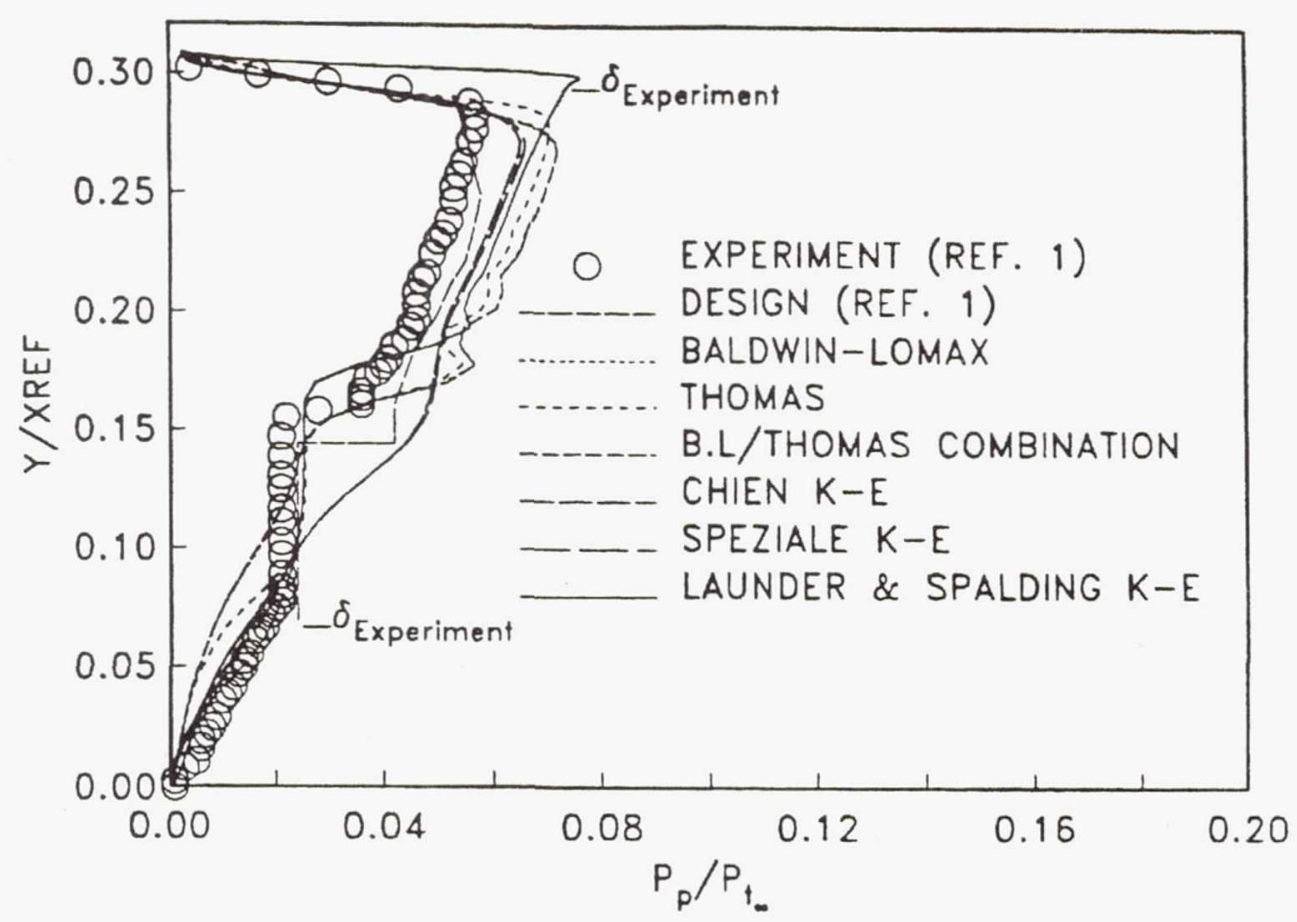

Figure 5.-Pitot pressure distribution at $\mathrm{X} / \mathrm{XREF}=5.67$.

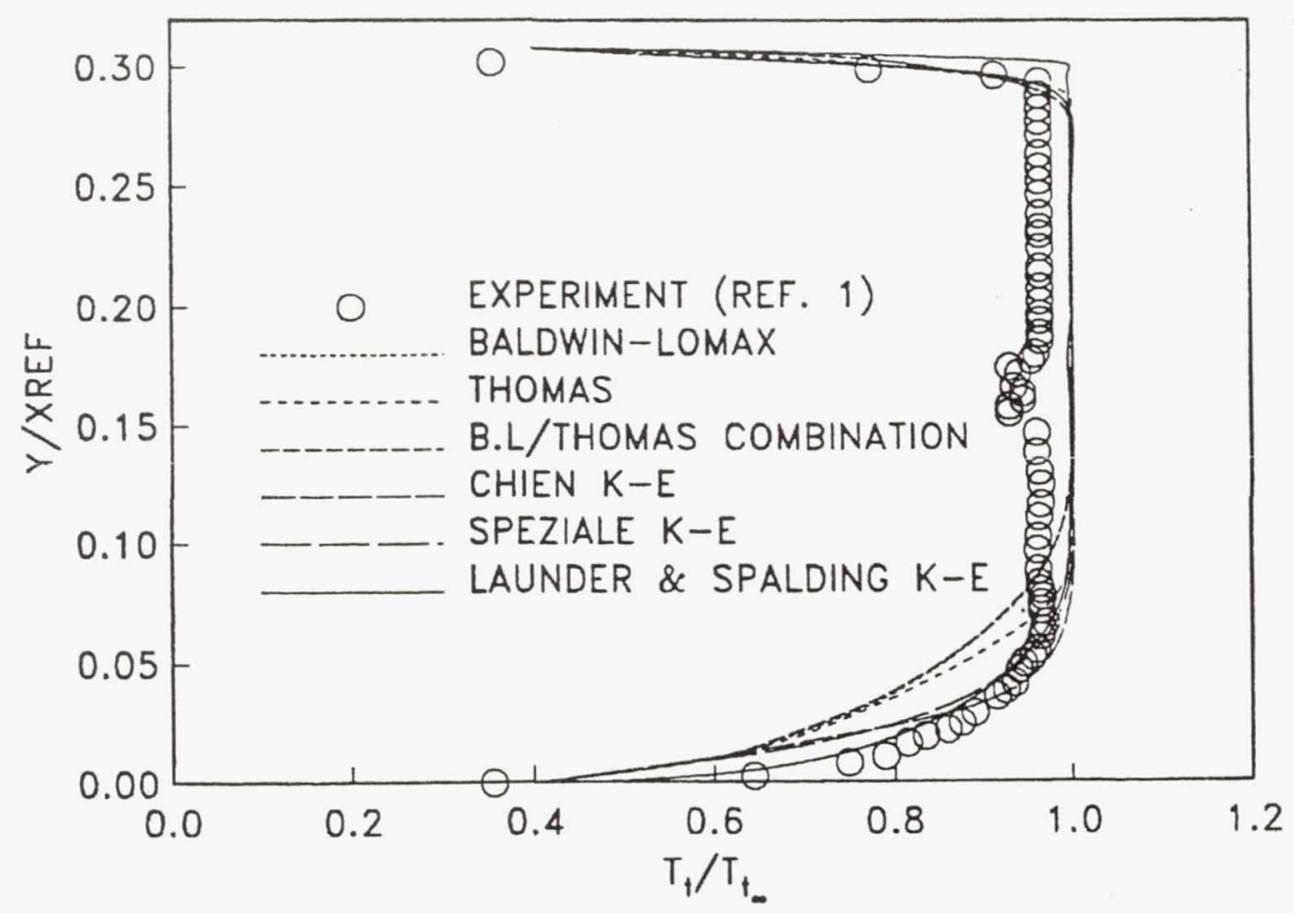

Figure 6.-Total temperature distribution at $\mathrm{X} / \mathrm{XREF}=5.67$. 


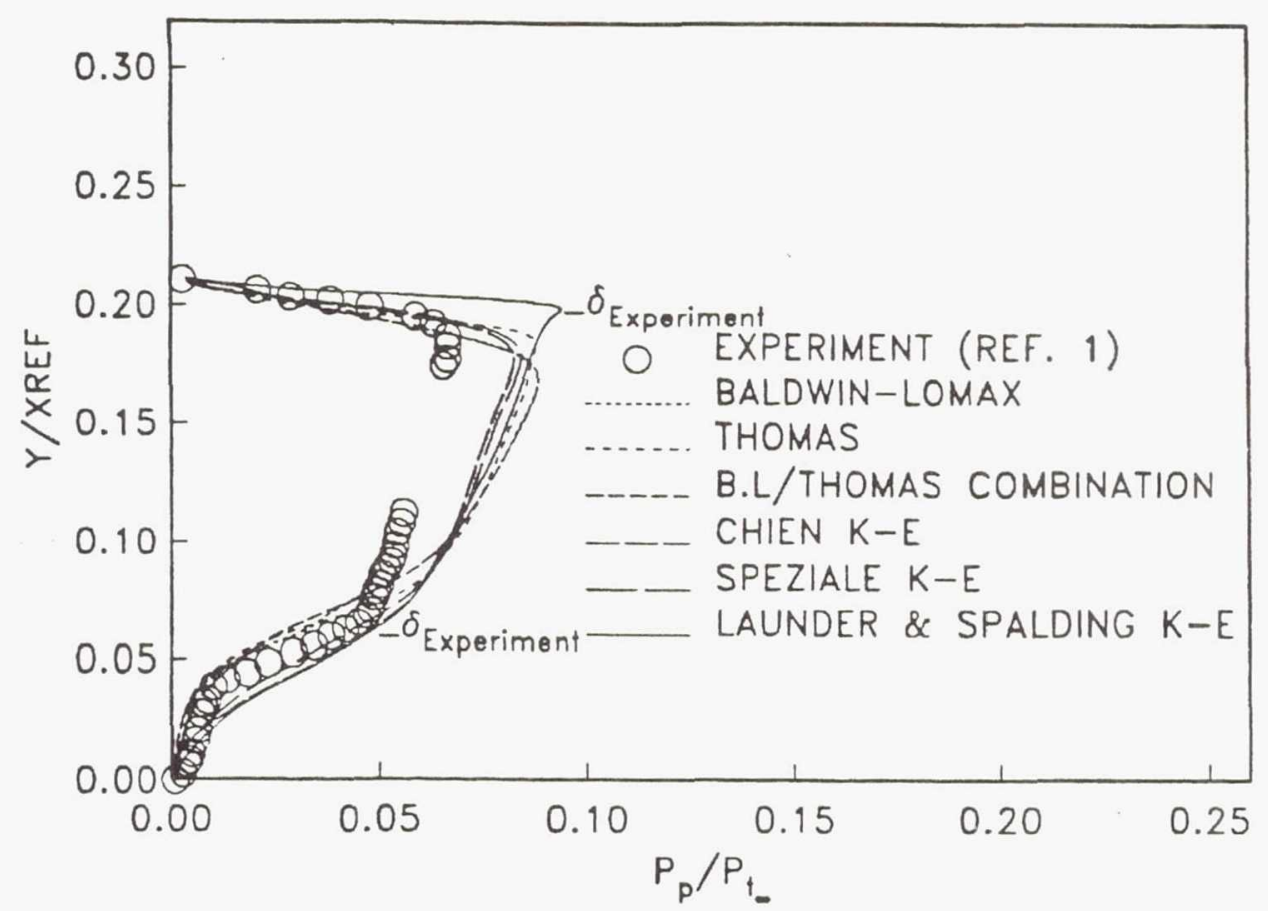

Figure 7.-Pitot pressure distribution at $\mathrm{X} / \mathrm{XREF}=6.09$.

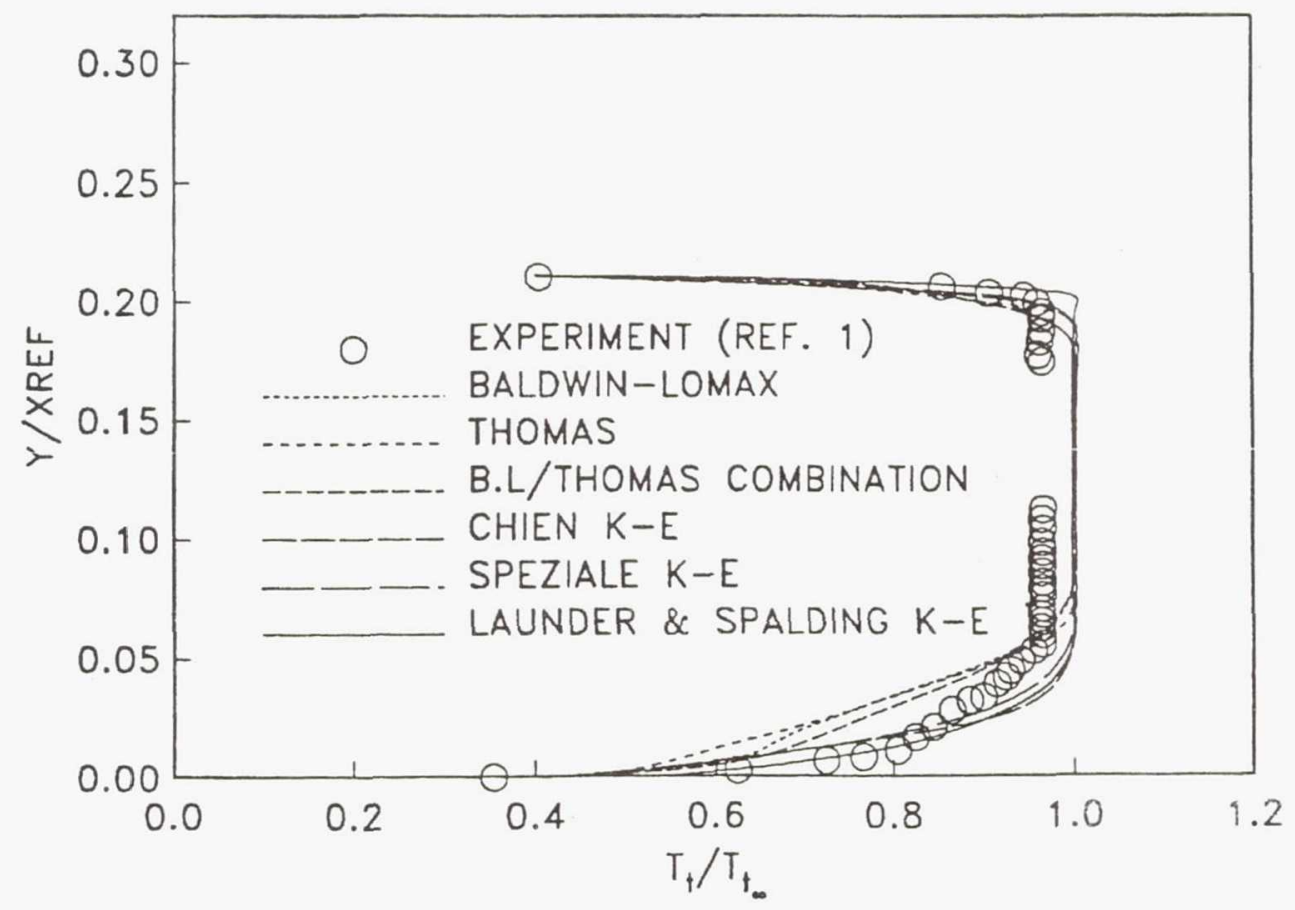

Figure 8. -Total temperature distribution at $X / X R E F=6.09$. 


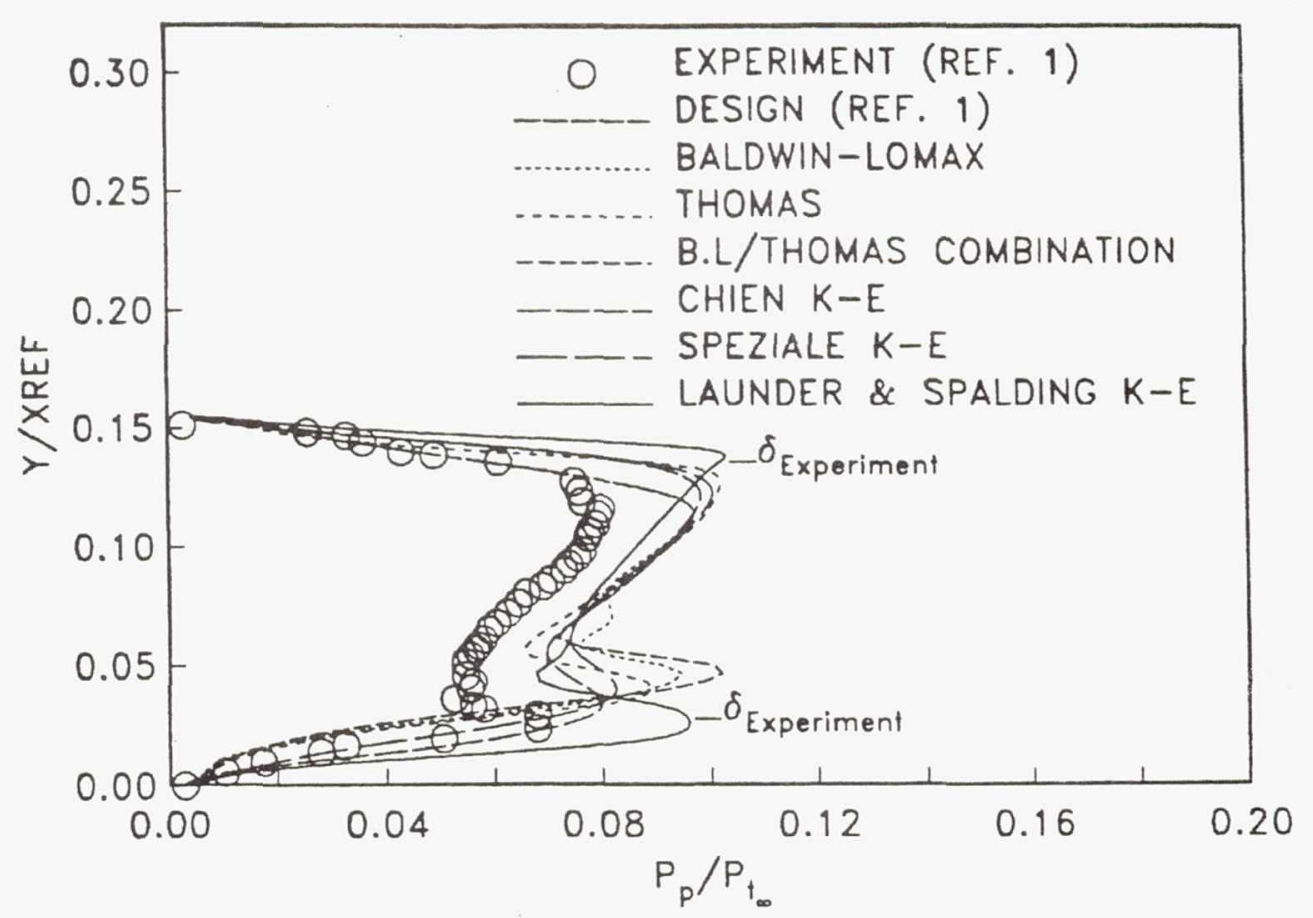

Figure 9.-Pitot pressure distribution at $\mathrm{X} / \mathrm{XREF}=6.37$.

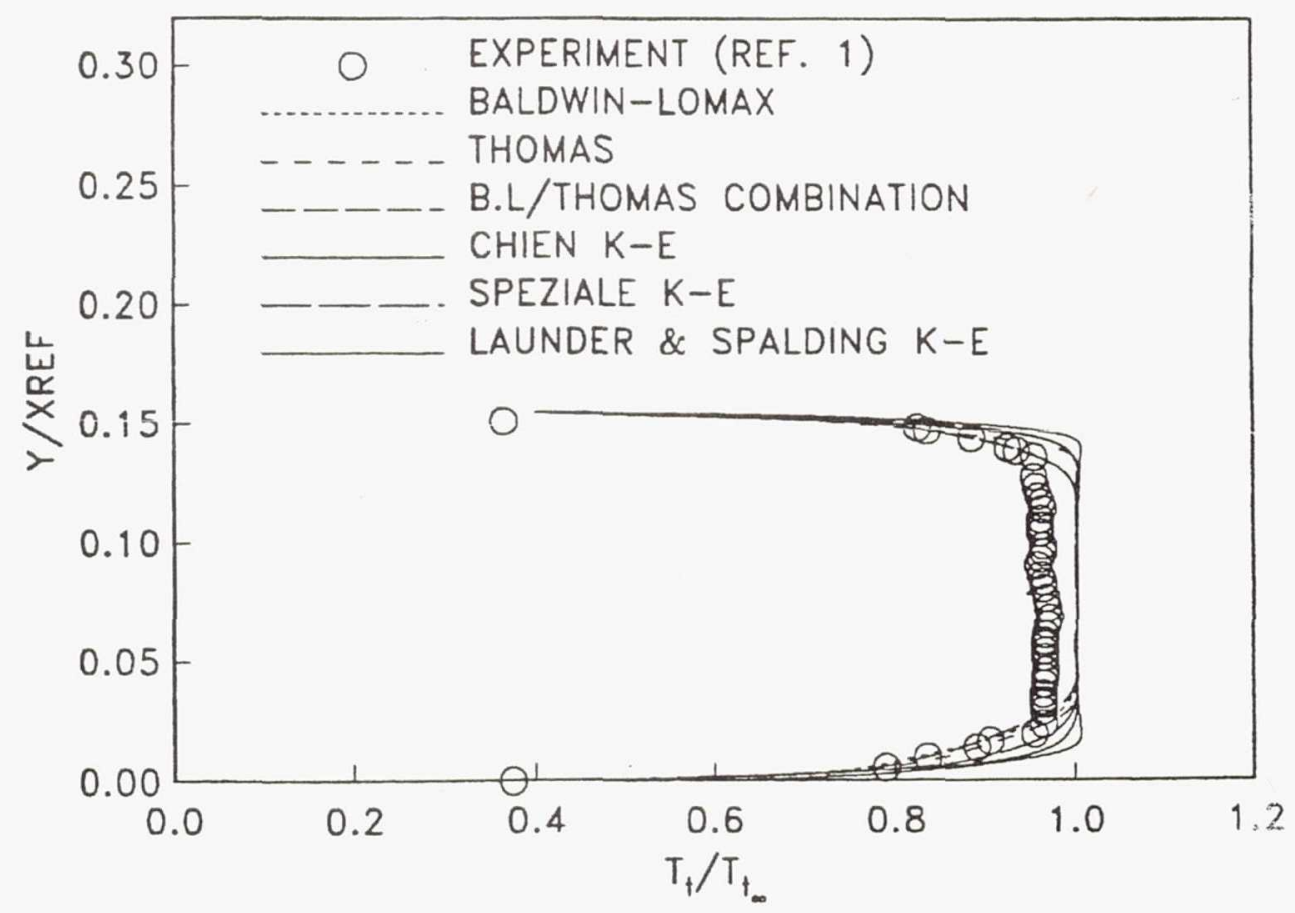

Figure 10.-Total temperature distribution at $\mathrm{X} / \mathrm{XREF}=6.37$. 


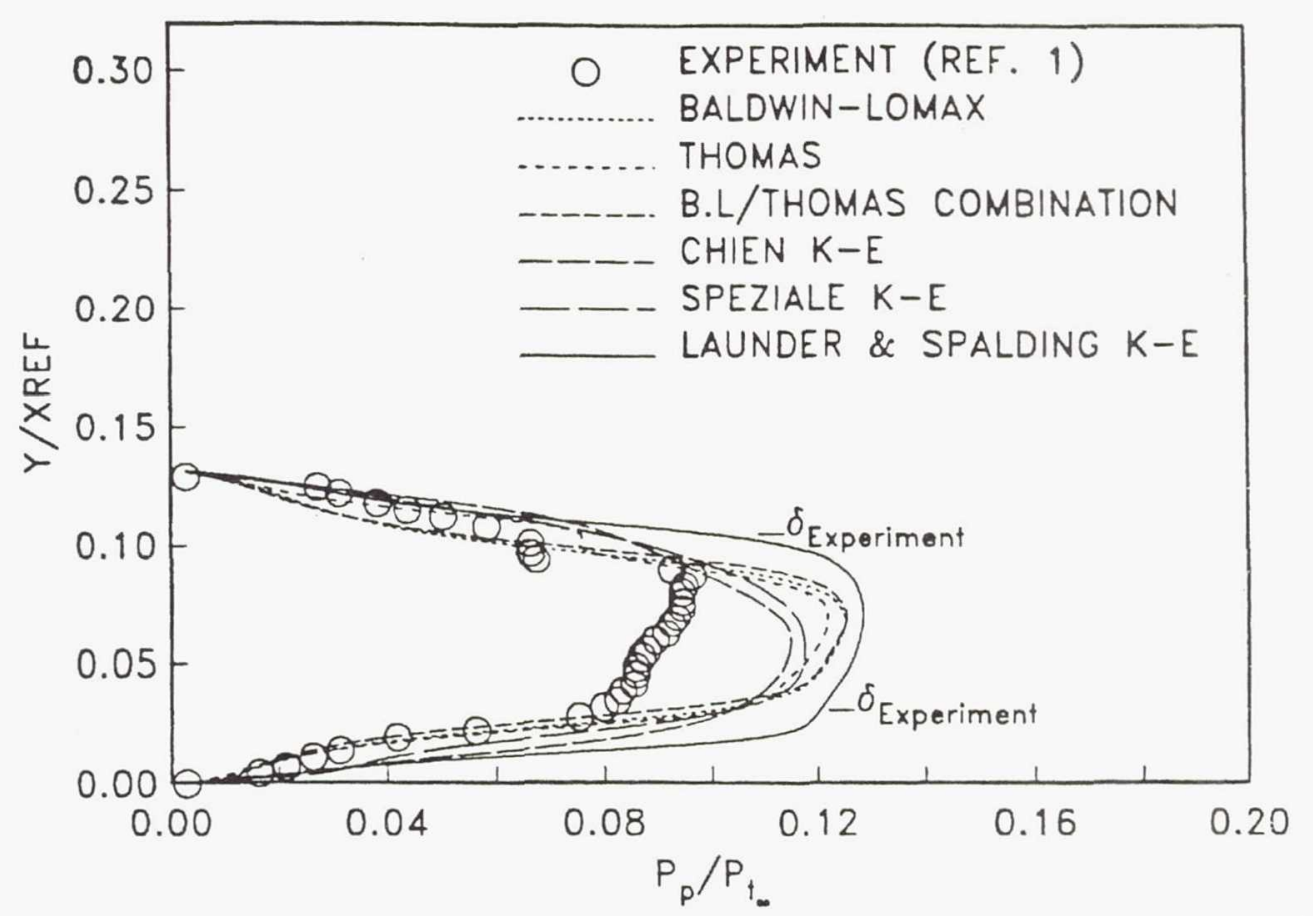

Figure 11.-Pitot pressure distribution at $\mathrm{X} / \mathrm{XREF}=6.65$.

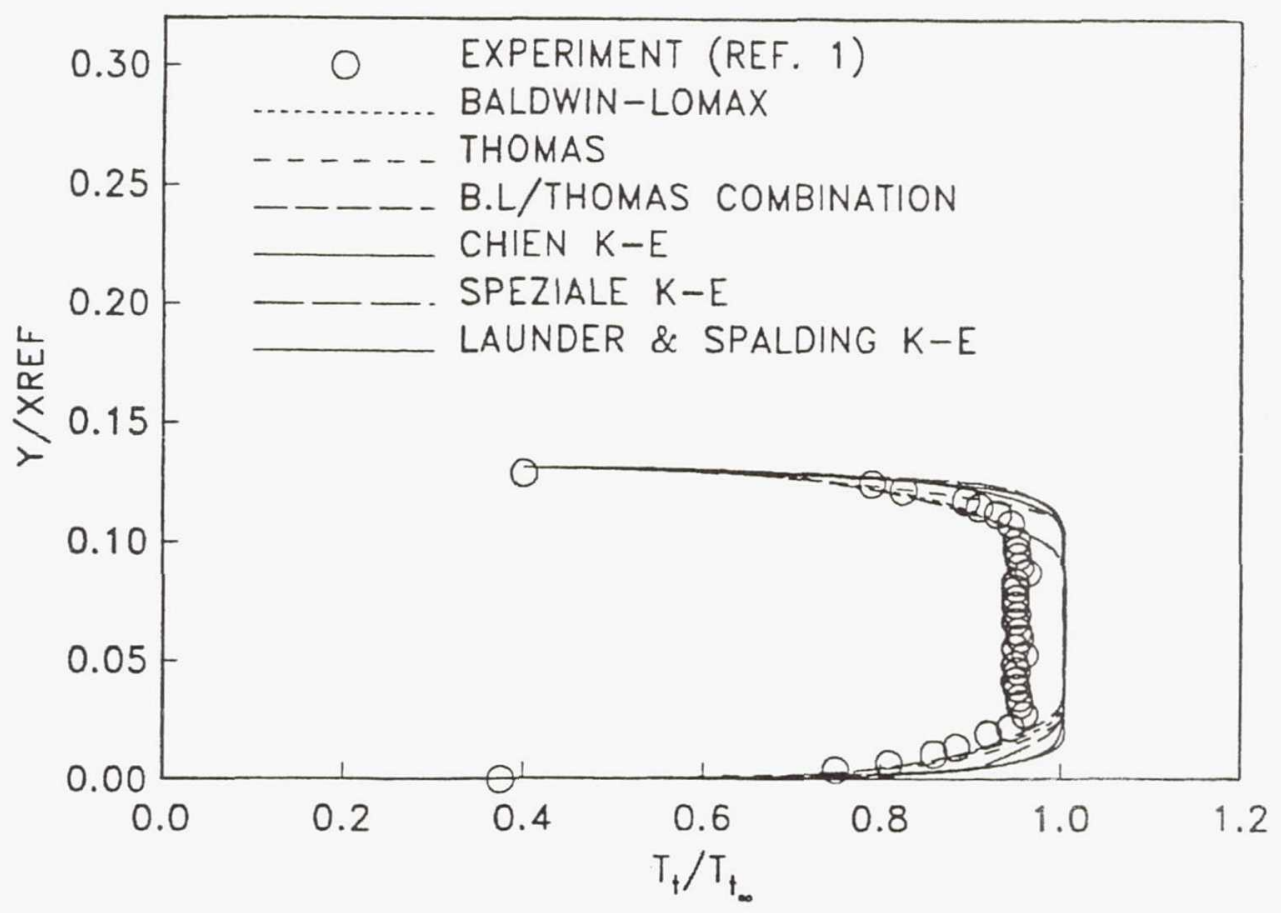

Figure 12.-Total temperature distribution at $\mathrm{X} / \mathrm{XREF}=6.65$. 


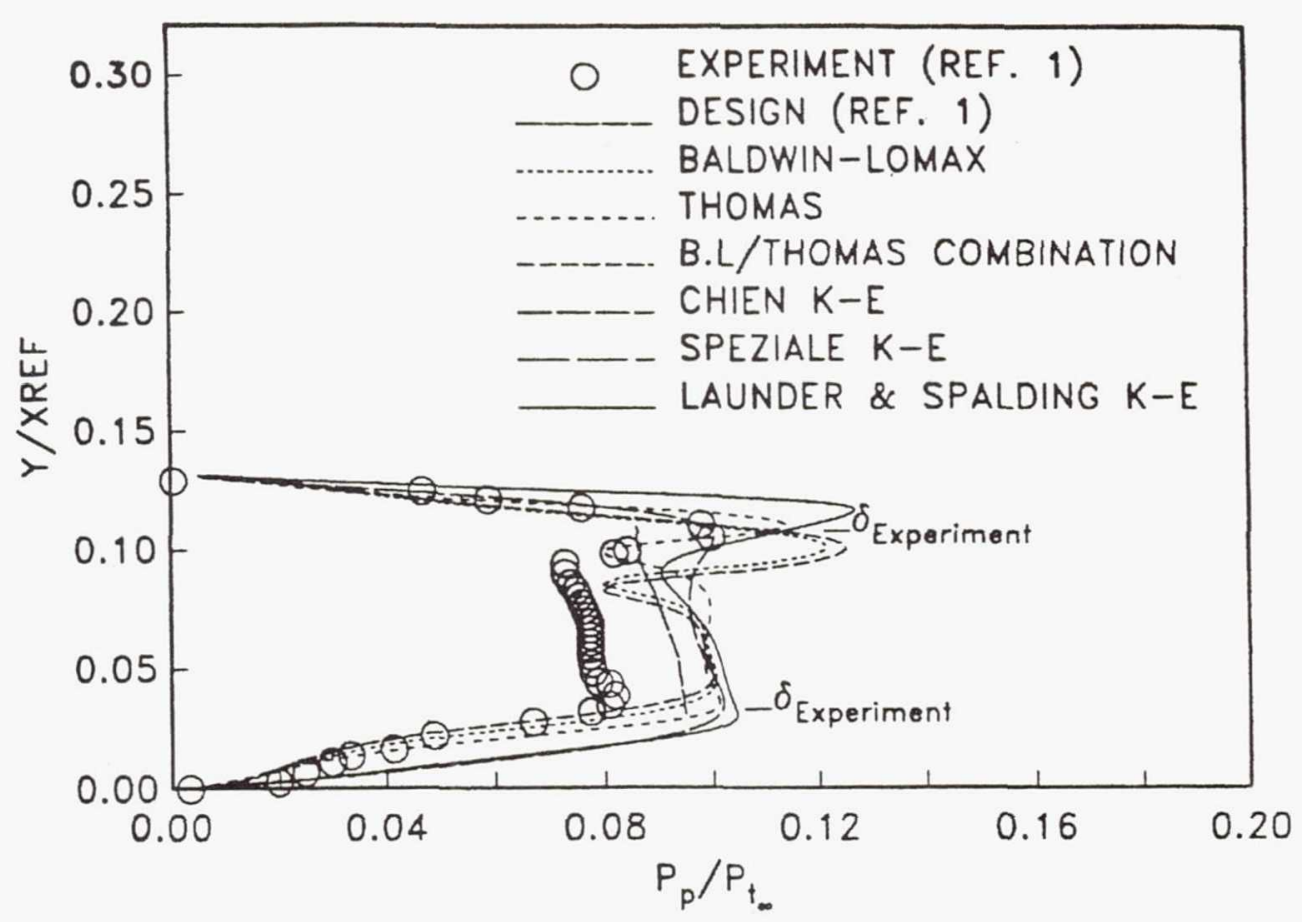

Figure 13.-Pitot pressure distribution at the throat of P8 iniet.

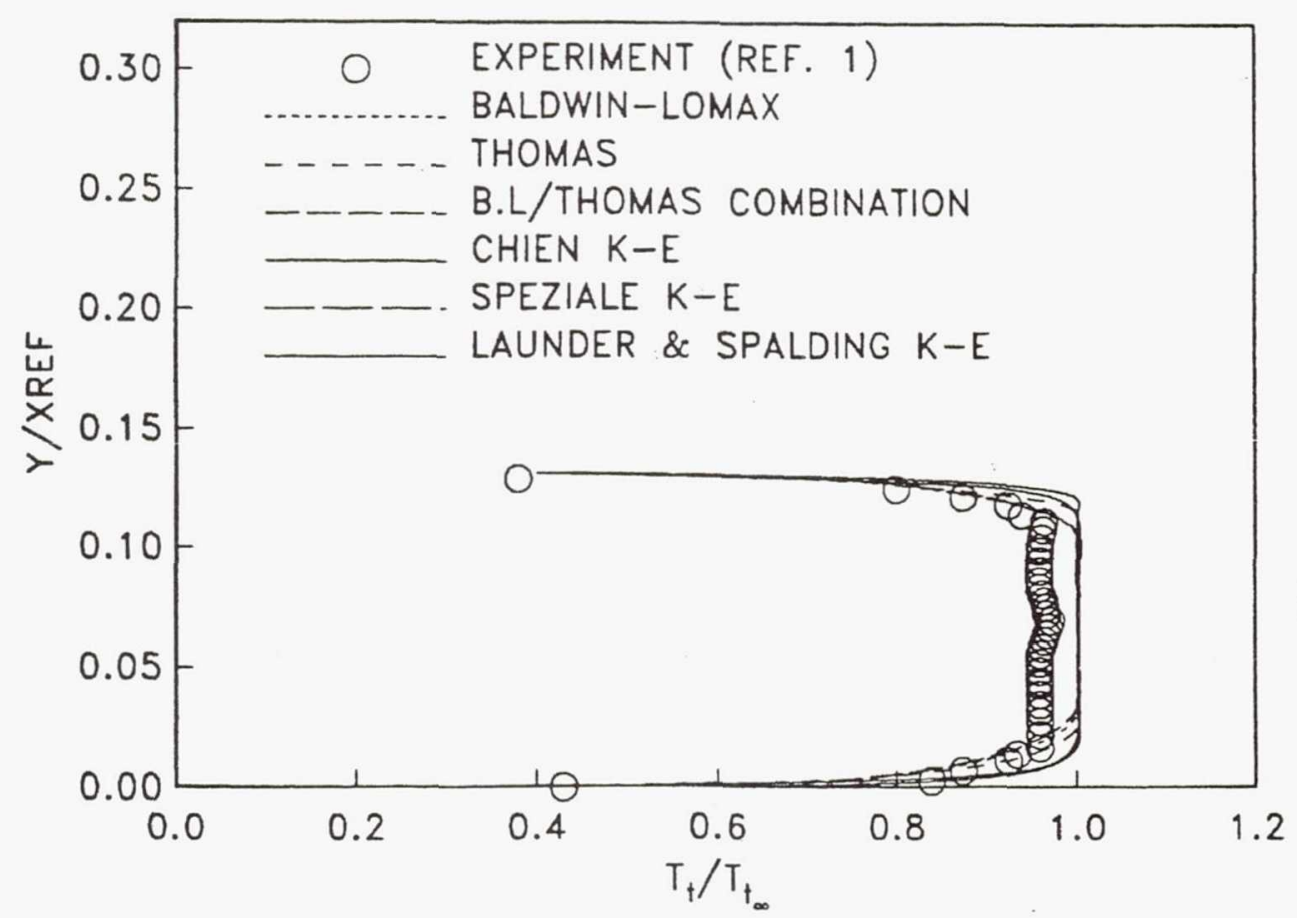

Figure 14.-Total pressure distribution at the throat of P8 inlet. 


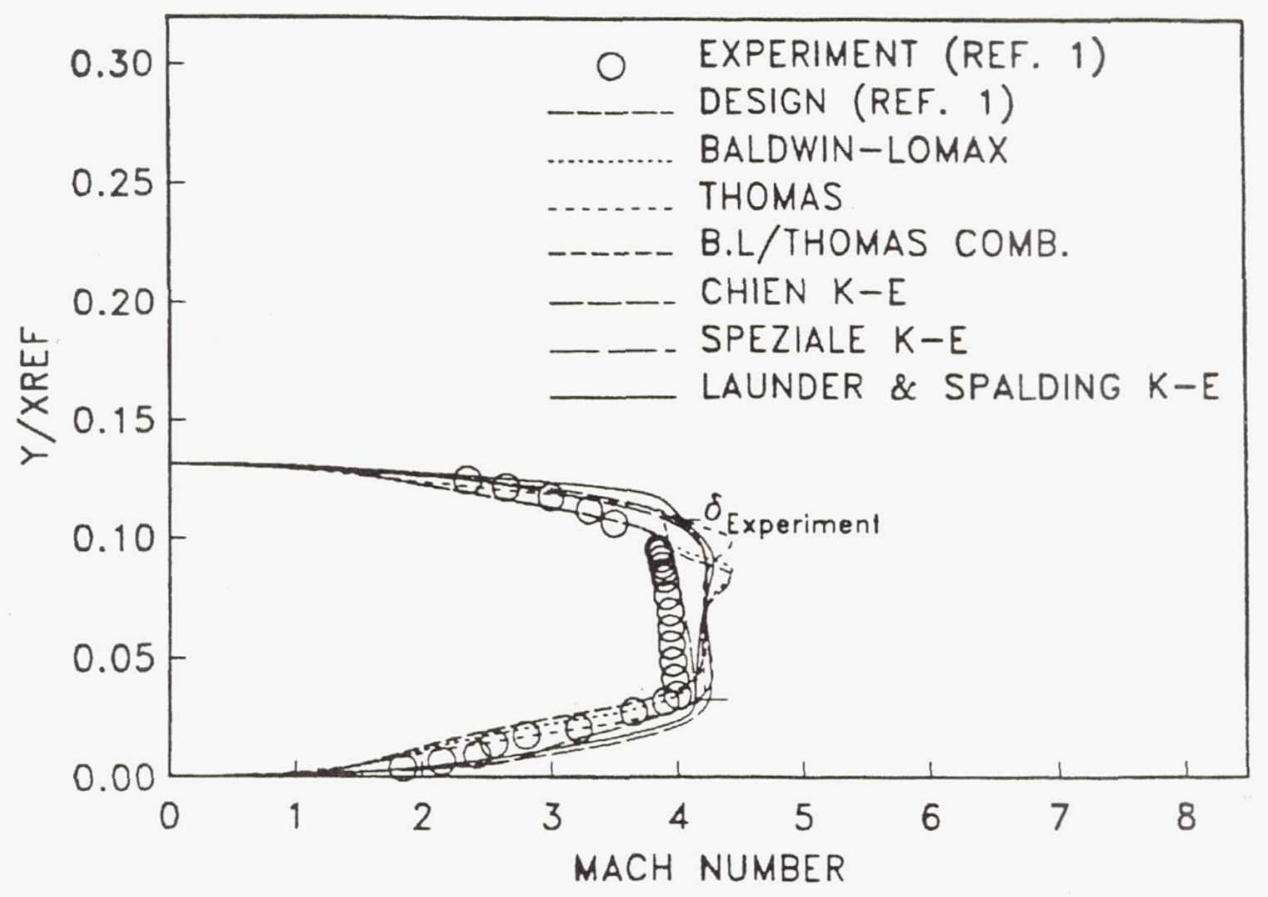

Figure 15.-Mach number distribution at the throat of P8 inlet. 
Public reporting burden for this collection of information is estimated to average 1 hour per response, including the time for reviewing instructions, searching existing data sources, gathering and maintaining the data needed, and completing and reviewing the collection of information. Send comments regarding this burden estimate or any other aspect of this collection of information, including suggestions for reducing this burden, to Washington Headquarters Services, Directorate for information Operations and Reports, 1215 Jefferson Davis Highway, Suite 1204, Arlington, VA 22202-4302, and to the Office of Management and Budget, Paperwork Reduction Project (0704-0188), Washington, DC 20503.

\begin{tabular}{l|l|l} 
1. AGENCY USE ONLY (Leave blank) & $\begin{array}{c}\text { 2. REPORT DATE } \\
\text { July } 1992\end{array}$ & $\begin{array}{r}\text { 3. REPORT TYPE AND DATES COVERED } \\
\text { Technical Memorandum }\end{array}$
\end{tabular}

\section{TITLE AND SUBTITLE}

Comparative Study of Turbulence Models in Predicting

Hypersonic Inlet Flows

6. AUTHOR(S)

Kamlesh Kapoor, Bernhard H. Anderson, and Robert J. Shaw
5. FUNDING NUMBERS

$$
\text { WU-505-62-40 }
$$

\section{PERFORMING ORGANIZATION NAME(S) AND ADDRESS(ES)}

National Aeronautics and Space Administration

Lewis Research Center

Cleveland, Ohio 44135-3191

9. SPONSORING/MONITORING AGENCY NAMES(S) AND ADDRESS(ES)

National Aeronautics and Space Administration

Washington, D.C. 20546-0001
8. PERFORMING ORGANIZATION REPORT NUMBER

E-7116

\section{SUPPLEMENTARY NOTES}

Prepared for the 28th Joint Propulsion Conference and Exhibit cosponsored by AIAA, SAE, ASME, and ASEE, Nashville, Tennessee, July 6-8, 1992. Kamlesh Kapoor, National Research Council-NASA Research Associate at Lewis Research Center. Bernhard H. Anderson and Robert J. Shaw, NASA Lewis Research Center.

12a. DISTRIBUTION/AVAILABILITY STATEMENT

Unclassified - Unlimited

Subject Category 02

\section{ABSTRACT (Maximum 200 words)}

A numerical study was conducted to analyze the performance of different turbulence models when applied to the hypersonic NASA P8 inlet. Computational results from the PARC2D code, which solves the full two-dimensional Reynolds-averaged Navier-Stokes equations, have been compared with experimental data. The zero-equation models considered for the study were the Baldwin-Lomax model, the Thomas model, and a combination of the BaldwinLomax and Thomas models; the two-equation models considered were the Chien model, the Speziale model (both low Reynolds number), and the Launder and Spalding model (high Reynolds number). The Thomas model performed best among the zero-equation models, and predicted good pressure distributions. The Chien and Speziale models compared very well with the experimental data, and performed better than the Thomas model near the walls.

\section{SUBJECT TERMS}

Hypersonic inlets; Computational fluid dynamics; Turbulence modeling; Internal flows

17. SECURITY CLASSIFICATION OF REPORT Unclassified
18. SECURITY CLASSIFICATION OF THIS PAGE Unclassified
19. SECURITY CLASSIFICATION OF ABSTRACT Unclassified
15. NUMBER OF PAGES 